\title{
Impact of a three-month resistance training program for elderly persons with knee osteoarthritis residing in the community of Santa Cruz, Rio Grande do Norte, Brazil
}

Rosa Sá de Oliveira Neta ${ }^{\longrightarrow}$

Frank Kleber de Lima Jr.'

Tiago Delfino Paival Mayra Carmem de Medeiros' Renata Trajano Jorge Caldas ${ }^{2}$ Marcelo Cardoso de Souza ${ }^{1}$

\section{Abstract}

Objective: to evaluate the impact of a three-month resistance exercise program on the pain and functionality of elderly patients with knee osteoarthritis from the city of Santa Cruz, Rio Grande do Norte. Method: a quasi-experimental study was performed with 13 elderly patients diagnosed with knee osteoarthritis, who underwent a resistance training program twice a week for 12 weeks. Pain, muscle strength, functionality, quality of life and patient satisfaction were evaluated using the following instruments: the visual analog scale, one repetition maximum testing, the Western Ontario and McMaster Universities Osteoarthritis Index, the Timed Up and Go Test, the 6-minute walk Test, the Short Form (36) Health Survey and the Likert scale. The paired T-test and ANOVA for repeated measures were used for statistical analysis. Results: the mean age of the patients was 62.0 $( \pm 10.0)$ years. At the end of the study, the pain, muscle strength, functional status and some areas of quality of life of the elderly had improved. Conclusion: resistance exercises were an effective and safe method of improving the pain, muscle strength, functionality and quality of life of the population studied. The elderly should be encouraged to perform supervised strength training therapy.

\footnotetext{
Universidade Federal do Rio Grande do Norte (UFRN), Faculdade de Ciências da Saúde do Trairi (FACISA), Clínica Escola de Fisioterapia. Santa Cruz, Rio Grande do Norte, Brasil.

2 Faculdade Santa Terezinha (CEST), Curso de Fisioterapia. São Luís, Maranhão, Brasil.
}

Keywords: Resistance training. Elderly. Knee. Osteoarthritis. 


\section{INTRODUCTION}

Osteoarthritis (OA) is the most common joint disease in the world, with the knee the most affected joint. It is a multifactorial disease which involves inflammatory, degenerative, genetic, hormonal and mechanical factors. Several risk situations have been identified: anterior cruciate ligament rupture, meniscectomy, knee injuries, knee varus or valgus deformity, and obesity. It is essential to promote antiobesity programs by targeting priority patients who have other risk factors such as a history of meniscectomy or knee injuries, or poor knee alignment ${ }^{1}$.

Among rheumatic diseases, OA represents about $30-40 \%$ of medical consultations in rheumatology outpatient clinics, and affects more than 250 million people worldwide ${ }^{2}$. Statistics suggest that over the next 20 years, the number of people affected by the disease in the USA will grow from approximately 43 million to 60 million, increasing chronic disease spending by more than $25 \%{ }^{3}$. In Brazil, it is estimated that $4 \%$ of the population suffers from OA, with the knee being the second most affected joint, representing $37 \%$ of cases ${ }^{4}$.

According to the American College of Rheumatology (ACR), OA is characterized by degeneration of the articular cartilage, crepitation, pain that worsens with weight support and improves with rest, joint stiffness, movement limitation, muscular weakness and varying degrees of local inflammation, and negatively interferes in the quality of life of these patients ${ }^{5,6}$.

Regarding functional status, approximately $80 \%$ of individuals with knee or hip OA have movement limitation and 25\% cannot perform the majority of their activities of daily living ${ }^{7}$. A qualitative review of a group of women aged 65 to 92 years showed that the main daily activities that are impaired in patients with $\mathrm{OA}$ of the lower limbs are: hygiene, dressing, locomotion, personal care and home maintenance ${ }^{8-11}$.

Muscle weakness of the quadriceps is also a common occurrence in the majority of patients with OA of the knees ${ }^{12,13}$. Perhaps because of this, studies investigating the use of strengthening exercises in these individuals have generally emphasized muscle strengthening through resistance exercises.
Osteoarthritis of the knee is therefore a major public health problem and may lead to severe disability. Based on the fact that there is no single protocol of effective resistance exercise for improving muscle function and strength for the treatment of elderly persons with this disease, the objective of this study was to evaluate the impact of a three-month program of resistance exercises on the pain and functionality of elderly patients with osteoarthritis of the knees in the city of Santa Cruz, Rio Grande do Norte.

\section{METHOD}

A quasi-experimental study was carried out in the Clínica Escola de Fisioterapia da Faculdade de Ciências da Saúde do Trairi (the Clinical Physiotherapy School of the Trairi Health Sciences College) (FACISA), of the Universidade Federal do Rio Grande do Norte (Rio Grande do Norte Federal University) (UFRN), in the city of Santa Cruz, in the rural part of the state of Rio Grande do Norte.

We evaluated 13 elderly patients, selected for convenience, with a medical diagnosis with unilateral or bilateral primary knee OA according to the criteria of the ACR5, and who presented pain between 3 and 8 centimeters in the $10-\mathrm{cm}$ visual analogue scale $(V A S)^{14}$ for pain in one or both knees. Data was collected in the second half of 2015 .

This research emerged from an extension project carried out based on the need to expedite the care of these patients, who were on the waiting list of the Physiotherapy Medical School of FACISA/UFRN. The study was approved by the Research Ethics Committee of Trairi Health Sciences College, under opinion No. 1,376,142, according to Resolution No. 466/2012 of the National Health Council. All patients read and signed a Free and Informed Consent Form.

Patients with inflammatory diseases or any medical condition that did not allow physical activity, who had suffered infiltration in the last three months, had performed regular physical activity in the last three months, or had a trip planned in the next 12 weeks were excluded.

The patients were evaluated at week 0 ('T0), week 4 (T4), week 8 (T8) and week 12 (T12), and the following instruments were applied based on these periods: 
- Visual analogue scale (VAS) for evaluation of pain at T0, T4, T8 and T12. The pain scale ranges from zero centimeters (without pain) to 10 centimeters (unbearable pain) ${ }^{14}$.

- The one repetition maximum (1RM) muscle strength test to evaluate the muscular strength of the quadriceps, hamstring, adductor and abductor muscles of the hip at T0, T4, T8 and T12. This was performed by calculating the $1 \mathrm{RM}$, which indicates the maximum load sustained in a single repetition. The test was performed by incrementally adding load according to the pain limit of the patient. Up to five attempts were allowed to identify the maximum load the patient could sustain when executing the movement. A rest period of up to five minutes between the trials was applied. The maximum load was determined considering ease and the proper pattern of movement execution ${ }^{15}$.

- The Likert scale for assessing patient satisfaction with the proposed treatment at $\mathrm{T} 4, \mathrm{~T} 8$ and $\mathrm{T} 12$. This is a scale used to evaluate the patient's satisfaction with the treatment that addresses the following: a) I feel much worse, b) I feel a little worse, c) unchanged, d) I feel a little better and e) I feel much better ${ }^{16}$.

- Timed Up and Go (TUG) test to evaluate functionality at $\mathrm{T} 0$ and $\mathrm{T} 12$. This is a functional test which consists of getting up from a chair, without using the arms, then walking for three meters, turning, and walking back. At the beginning of the Test, the patient should have his or her back resting on the back of the chair. The patient received a "go" instruction to perform the test and the timing was calculated from this voice command until the moment he or she again rested his or her back on the back of the chair ${ }^{17}$.

- Six-minute walk test (6MWT) to evaluate functionality at T0 and T12. Although this test developed to evaluate the physical capacity of patients with cardiopulmonary diseases, this test has also been used (with some adaptations) to measure the walking performance of patients with motor difficulties. The test was performed on a 20-meter marked lane in a sports court closed to the movement of other people. Patients were instructed to walk the entire lane and could interrupt the Test if they did not feel able to continue ${ }^{18}$.

\section{- Western Ontario McMaster Universities Osteoarthritis} Index (WOMAC) to evaluate functionality at $\mathrm{T} 0$ and T12: a three-dimensional questionnaire assessing pain, joint stiffness and function. It is specific for the evaluation of patients with knee OA and scores vary from 0-96, with the higher the final score, the worse the condition of the individual. This questionnaire was translated into Portuguese and validated in $2003^{19}$.

- ShortForm-36 (SF-36) to evaluate quality of life at $\mathrm{T} 0$ and $\mathrm{T} 12$. This is a generic questionnaire with 36 items divided into domains such as functional capacity, physical limitation, pain, general health, vitality, social aspects, emotional aspects and mental health. A score ranging from $0-100$ is provided, with 100 being the best state of health possible and 0 being the worst ${ }^{20}$.

The exercise program was specifically based on muscle strengthening and lasted 12 weeks, as shown in Figure 1.

Figure 1. Exercise program carried out. Santa Cruz, Rio Grande do Norte, 2015.

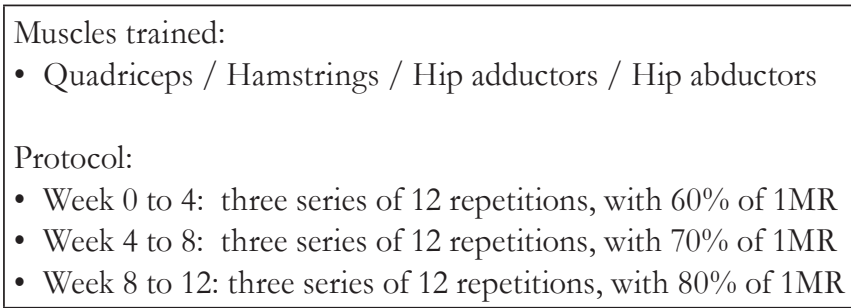

1MR: one maximum repetition test for muscle strength 
In statistical analysis, repeated measures analysis (ANOVA) was performed to compare the VAS, Likert and 1MR Test, with Bonferroni post hoc. The paired t-test was used for the 6MW'T, TUG, WOMAC and SF-36 results. For data analysis, Shapiro-Wilk statistical treatments and analysis of distribution by the Q-Q normality graph was performed. The results obtained in the analysis of the distribution indicated normality for all variables for $\mathrm{p}<0.05$.

\section{RESULTS}

The mean age of the patients was $62.0( \pm 10.0)$ years and the mean body mass index (BMI) was 30.9 ( \pm 3.7$) \mathrm{kg} / \mathrm{m} 2$. Only two of the elderly persons were male. Six declared themselves their skin color/ ethnicity to be white/Caucasian, five said they were black/Afro-Brazilian and two said they were brown/ mixed race. The elderly persons had an average of six years of schooling. Five were retired, four said they had a non-manual job and four said they had a manual job.

A significant statistical difference $(\mathrm{p}=0.02)$ was observed between the first week (T0) and the fourth and eighth weeks (T4 and T8), in the improvement of knee pain (Table 1).

The behavior of the Likert scale results did not show a significant difference between the assessment times.

Following 12 weeks of intervention there were improvements in load for the one maximum repetition (1MR) test for all the muscles trained (Table 2).

The results for the 6MWT did not differ significantly $(p=0.7)$ after 12 weeks of intervention. The TUG variable exhibited the same behavior $(\mathrm{p}=0.7)$ over the same period. The scores of the WOMAC variables: pain, function and total exhibited a significant difference $(\mathrm{p}=0.01)$ after 12 weeks of intervention. However, the variable stiffness did not differ significantly $(p=0.08)$ over the intervention period (Table 3).

The functional capacity, pain, vitality, mental health and emotional aspects domains displayed a significant difference when the before and after time periods were compared. The domains social aspects, limitation by physical aspects and general health status did not exhibit significant alterations (Table 4).

\section{DISCUSSION}

As observed, the resistance exercise program of the present study was effective in improving pain in the knees of the surveyed elderly persons, although no difference in satisfaction with treatment was found using the Likert scale. Other studies ${ }^{21}$ corroborate these findings, showing that weight exercises are effective in improving the pain of these patients.

There was also improvement in muscle strength for the four trained muscle groups, which again proved the effectiveness of this training program. It is important to emphasize that these exercises are easy to perform, although supervision is necessary, especially in the studied age group.

In addition to quadricep weakness, recent studies have shown that individuals with knee OA have lower isokinetic hip performance than do healthy controls ${ }^{22-24}$. Corroborating this finding, a cohort study with a three-year follow-up showed that the decrease in the muscular strength of the hip abductors together with the presence of comorbidities are prognostic factors for increased

Table 1. Description of visual analog scale for pain (VAS) of the 13 elderly persons during 12 weeks of resistance exercises. Santa Cruz, Rio Grande do Norte, 2015.

\begin{tabular}{llll}
\hline Weeks & Mean (sd) & \multicolumn{2}{l}{ Confidence Interval 95\% } \\
\cline { 3 - 4 } & & Lower & Upper \\
\hline T0: initial assessment & $5.15( \pm 1.72)$ & 4,11 & 6.20 \\
\hline T4: assessment in week 4 & $3.08( \pm 2.53)^{*}$ & 1,55 & 4.61 \\
\hline T8: assessment in week 8 & $2.62( \pm 2.26)^{*}$ & 1,25 & 3.98 \\
\hline T12: assessment in week 12 & $3.31( \pm 2.02)$ & 2,09 & 4.53 \\
\hline
\end{tabular}

$* \mathrm{p}=0.02 ;$ Repeated measures ANOVA. 
Table 2. Behavior of load represented in kilograms for each muscle group during training program. Santa Cruz, Rio Grande do Norte, 2015.

\begin{tabular}{llllll}
\hline & & \multicolumn{3}{c}{ Weeks } & \\
\multirow{2}{*}{ Muscles } & $\begin{array}{l}\text { T0: Initial } \\
\text { assessment }\end{array}$ & $\begin{array}{l}\text { T4: Assessment in } \\
\text { week } 4\end{array}$ & $\begin{array}{l}\text { T8: Assessment in } \\
\text { week } 8\end{array}$ & $\begin{array}{l}\text { T12: Assessment in } \\
\text { week 12 }\end{array}$ \\
& Mean (sd) & Mean (sd) & Mean (sd) & Mean (sd) & $p$ \\
\hline Quadriceps & $10.4( \pm 4.9)$ & $16.5( \pm 7.7)$ & $17.1( \pm 9.8)$ & $20.4( \pm 11.3)$ & $0.03^{*}$ \\
\hline Hamstring & $5.0( \pm 1.7)$ & $8.0( \pm 3.0)$ & $9.5( \pm 3.2)$ & $11.0( \pm 3.3)$ & $0.01^{*}$ \\
\hline Adductors & $5.0( \pm 1.9)$ & $8.6( \pm 2.8)$ & $9.5( \pm 3.0)$ & $11.3( \pm 3.0)$ & $0.01^{*}$ \\
\hline Abductors & $4.8( \pm 2.0)$ & $8.0( \pm 2.4)$ & $10.1( \pm 3.1)$ & $11.7( \pm 3.2)$ & $0.01^{*}$ \\
\hline
\end{tabular}

$* \mathrm{p}<0.05$; Repeated measures ANOVA; sd: Standard-deviation.

Table 3. Results of tests and functional assessment of 13 elderly persons after 12 weeks of resistance exercises. Santa Cruz, Rio Grande do Norte, 2015.

\begin{tabular}{llll}
\hline \multirow{2}{*}{ Variable } & \multicolumn{2}{c}{ Weeks } & \\
& To: Initial assessment & T12: Week 12 assessment & \\
\hline TC6min & $395.3( \pm 69.5)$ & Mean $(\mathrm{sd})$ & 0.7 \\
\hline Timed Up and Go & $11.1( \pm 2.7)$ & $404.2( \pm 90.9)$ & 0.7 \\
\hline Womac domínio dor & $9.5( \pm 3.0)$ & $10.9( \pm 2.3)$ & $0.01^{*}$ \\
\hline Womac domínio função & $34.3( \pm 1.9)$ & $6.1( \pm 4.0)$ & $0.01^{*}$ \\
\hline Womac domínio rigidez & $3.9( \pm 1.6)$ & $23.1( \pm 13.1)$ & 0.08 \\
\hline Womac escore total & $49.1( \pm 14.8)$ & $3.1( \pm 1.9)$ & $0.01^{*}$ \\
\hline
\end{tabular}

${ }^{*} \mathrm{p}<0.05$; Paired t-test; 6MWT: Six-minute walk test; WOMAC: Western Ontario McMaster Universities Osteoarthritis Index; sd; standard deviation.

Table 4. Results for Short Form-36 (SF-36) domains for 13 elderly persons submitted to 12 weeks of resistance exercises. Santa Cruz, Rio Grande do Norte, 2015.

\begin{tabular}{llll}
\hline & T0: initial assessment & T12: week 12 assessment & $p$ \\
Domains & Mean (sd) & Mean (sd) & $0.01^{*}$ \\
Functional capacity & $37.7( \pm 17.9)$ & $60.4( \pm 22.9)$ & $0.03^{*}$ \\
\hline Pain & $10.1( \pm 7.0)$ & $17.7( \pm 7.2)$ & $0.04^{*}$ \\
\hline Vitality & $40.0( \pm 16.3)$ & $55.4( \pm 22.1)$ & $0.02^{*}$ \\
\hline Mental health & $62.1( \pm 22.7)$ & $74.8( \pm 24.7)$ & 0.06 \\
\hline Social aspects & $66.5( \pm 28.1)$ & $79.9( \pm 29,0)$ & $0.02^{*}$ \\
Emotional aspects & $30.3( \pm 44.0)$ & $66.7( \pm 43,0)$ & 0.30 \\
\hline Limitation by physical aspects & $17.3( \pm 25.8)$ & $34.6( \pm 41.5)$ & 0.11 \\
\hline General health status & $53.1( \pm 20.8)$ & $62.3( \pm 22.6)$ & \\
\hline
\end{tabular}

${ }^{*} \mathrm{p}<0.05$; Paired t-Test; sd: standard deviation. 
functional limitation ${ }^{25}$. There is also evidence that muscle weakness of the hip abductors in patients with knee OA is associated with more rapid progression of disease ${ }^{22}$ and that each unit of increase during adduction increases the risk of disease progression ${ }^{26}$ and the intensity of pain ${ }^{27,28} 6.5$ times.

These exercises have proven benefits in restoring range of motion, strengthening the muscles, improving pain and promoting improvement in day-to-day activities such as walking, climbing and descending stairs and even participating in sports ${ }^{29,30}$.

A study by Jorge et al. ${ }^{31}$, evaluated the effectiveness of a progressive resistance exercise program in women with knee OA. The justification for the study was the fact that few studies to date had included the strengthening of hip muscles in rehabilitation programs for patients with knee OA. The study therefore evaluated the strengthening of the hip abductor and adductor muscles, with a gradual increase in load for patients with knee OA. The results of the study showed positive effects in relation to pain, function, some aspects of quality of life and in all measures of strength from the sixth week of training onwards.

Although muscle strength increased, no differences were found in the 6MWT and TUG. This can be explained by the small sample size and the fact that the elderly persons demonstrated good functional performance in pre-testing. It was expected that, with stronger muscles, they would walk greater distances and be faster in the TUG Test.

The WOMAC questionnaire is most used scale for the functional evaluation of patients with knee OA in global literature, as it is specific for this disease. Functional improvement was found in the patients studied, both in the total WOMAC value and in the pain and function domains, except for joint stiffness, again showing the importance of performing these exercises ${ }^{31}$.

Quality of life also improved in five of the eight domains of the SF-36 questionnaire, with recent studies showing that $\mathrm{OA}$ is associated with a lower quality of life ${ }^{32}$. The fact that no improvement was found in the other domains may be related to the small sample size, as well as the great variability of the responses of the patients.

The exercises of the training program used in this study can be considered effective, safe, utilize low cost materials, do not require large structures and can be easily performed in controlled environments.

It should be emphasized that the patients in this study were evaluated under specific conditions, which resulted in some limitations, such as: the small number of participants, the lack of sample calculation as the sample was convenience-based, and the lack of a control group with which to compare the results. However, the importance of encouraging the practice of physical activity focusing on muscle strengthening among the population is evident.

\section{CONCLUSION}

The proposed resistance exercise program was effective in improving the pain, muscle strength of the quadricep, hamstring, and hip adductor and abductor muscles; functional capacity, vitality, mental health and emotional aspects of quality of life in the elderly with osteoarthritis of the knees of the city of Santa Cruz, Rio Grande do Norte, Brazil.

\section{REFERENCES}

1. Flouzat-Lachaniette CH. At-risk situations for knee osteoarthritis. Rev Prat. 2012 ;62(5):630-4.

2. Bruyère $\mathrm{O}$, Cooper $\mathrm{C}$, Pelletier JP, Maheu $\mathrm{E}$, Rannou F, Branco J. A consensus statement on the European Society for Clinical and Economic Aspects of Osteoporosis and Osteoarthritis (ESCEO) algorithm for the management of knee osteoarthritis-From evidence-based medicine to the real-life setting. Semin Arthritis Rheum. 2016 Feb;45(4 Suppl):S3-11.
3. Dillon CF, Rasch EK, Gu Q, Hirsch R. Prevalence of knee osteoarthritis in the United States: arthritis data from the Third National Health and Nutrition Examination Survey 1991-94. J Rheumatol. 2006;33(11):2271-9.

4. Senna ER, De Barros AL, Silva EO, Costa IF, Pereira LV, Ciconelli RM, et al. Prevalence of rheumatic diseases in Brazil: a study using the COPCORD approach. J Rheumatol. 2004;31(3):594-7. 
5. Hochberg MC, Altman RD, April KT, Benkhalti M, Guyatt G, McGowan J, et al. American College of Rheumatology 2012 recommendations for the use of nonpharmacologic and pharmacologic therapies in osteoarthritis of the hand, hip, and knee. Arthritis Care Res (Hoboken). 2012 Apr;64(4):465-74.

6. Fernandes L, Hagen KB, Bijlsma JW, Andreassen O, Christensen P, Conaghan PG, et al. EULAR recommendations for the non-pharmacological core management of hip and knee osteoarthritis. Ann Rheum Dis. 2013 Jul;72(7):1125-35.

7. Brooks PM. Impact of osteoarthritis on individuals and society: how much disability? Social consequences and health economic implications. Curr Opin Rheumatol. 2002;14(5):573-7.

8. Nguyen C, Lefèvre-Colau MM, Poiraudeau S, Rannou F. Rehabilitation (exercise and strength training) and osteoarthritis: A critical narrative review. Ann Phys Rehabil Med. 2016 Jun;59(3):190-5.

9. Roos EM, Bremander AB, Englund M, Lohmander LS. Change in self-reported outcomes and objective physical function over 7 years in middle-aged subjects with or at high risk of knee osteoarthritis. Ann Rheum Dis. 2008;67(4):505-10.

10. Dekker J, van Dijk GM, Veenhof C. Risk factors for functional decline in osteoarthritis of the hip or knee. Curr Opin Rheumatol. 2009;21(5):520-4.

11. Fukutani N, Iijima H, Aoyama T, Yamamoto Y, Hiraoka M, Miyanobu K, et al. Knee pain during activities of daily living and its relationship with physical activity in patients with early and severe knee osteoarthritis. Clin Rheumatol. 2016 Sep;35(9):2307-16.

12. Cherian JJ, McElroy MJ, Kapadia BH, Bhave A, Mont MA. Prospective Case Series of NMES for Quadriceps Weakness and Decrease Function in Patients with Osteoarthritis of the Knee. J Long Term Eff Med Implants. 2015;25(4):301-6.

13. Vaz MA, Baroni BM, Geremia JM, Lanferdini FJ, Mayer A, Arampatzis A, et al. Neuromuscular electrical stimulation (NMES) reduces structural and functional losses of quadriceps muscle and improves health status in patients with knee osteoarthritis. J Orthop Res. 2013 Apr;31(4):511-6.

14. Scott J, Huskisson EC. Vertical or horizontal visual analogue scales. Ann Rheum Dis. 1979;38(6):560.

15. Verdijk LB, van Loon L, Meijer K, Savelberg HH. One-repetition maximum strength test represents a valid means to assess leg strength in vivo in humans. J Sports Sci. 2009 ;27(1):59-68.

16. Drinkwater BL. A comparison of the direction-ofperception technique with the Likert method in the measurement of attitudes. J Soc Psychol. 1965; 67 (2): 189-96.
17. Podsiadlo D, Richardson S. The timed "Up \& Go": a test of basic functional mobility for frail elderly persons. J Am Geriatr Soc. 1991; 39 (2): 142-8.

18. Brooks D, Solway S, Gibbons WJ. ATS statement on six-minute walk test. Am J Respir Crit Care Med. 2003; 167(9): 1287.

19. Fernandes MI. Tradução e validação do questionário de qualidade de vida específico para osteoartrose WOMAC (Western Ontario McMaster Universities) para a língua portuguesa [tese]. São Paulo: Universidade Federal de São Paulo; 2003.

20. Ciconelli RM, Ferraz MB, Santos W, Meinão I, Quaresma MR. Tradução para a língua portuguesa e validação do questionário genérico de avaliação de qualidade de vida SF-36 (Brasil SF-36). Rev Bras Reumatol. 1999; 39(3):143-50.

21. Li Y, Su Y, Chen S, Zhang Y, Zhang Z, Liu C, et al. The effects of resistance exercise in patients with knee osteoarthritis: a systematic review and meta-analysis. Clin Rehabil. 2016; 30(10):947-959.

22. Chang A, Hayes K, Dunlop D, Song J, Hurwitz D, Cahue $\mathrm{S}$, et al. Hip abduction moment and protection against medial tibiofemoral osteoarthritis progression. Arthritis Rheum. 2005;52(11):3515-9.

23. Bennell KL, Hunt MA, Wrigley TV, Hunter DJ, McManus FJ, Hodges PW, et al. Hip strengthening reduces symptoms but not knee load in people with medial knee osteoarthritis and varus malalignment: a randomised controlled trial. Osteoarthritis Cartilage. 2010;18(5):621-8.

24. Costa RA, Oliveira LM, Watanabe SH, Jones A, Natour J. Isokinetic assessment of the hip muscles in patients with osteoarthritis of the knee. Clinics (Sao Paulo). 2011;65(12):1253-9.

25. van Dijk GM, Veenhof C, Spreeuwenberg P, Coene N, Burger BJ, van Schaardenburg D, et al. Prognosis of limitations in activities in osteoarthritis of the hip or knee: a 3-year cohort study. Arch Phys Med Rehabil. 2010;91(1):58-66.

26. Hurwitz DE, Ryals AB, Case JP, Block JA, Andriacchi TP. The knee adduction moment during gait in subjects with knee osteoarthritis is more closely correlated with static alignment than radiographic disease severity, toe out angle and pain. J Orthop Res. 2002;20(1):101-7.

27. Hall M, Bennell KL, Wrigley TV, Metcalf BR, Campbell PK, Kasza J, et al. The knee adduction moment and knee osteoarthritis symptoms: relationships according to radiographic disease severity. Osteoarthritis Cartilage. 2016 Sep 8. pii: S1063-4584(16)30264-3. doi: 10.1016/j. joca.2016.08.014. [Epub ahead of print] 
28. Mikesky AE, Mazzuca SA, Brandt KD, Perkins SM, Damush T, Lane KA. Effects of strength training on the incidence and progression of knee osteoarthritis. Arthritis Rheum. 2006;55(5):690-9.

29. de Rooij M, van der Leeden M, Cheung J, van der Esch M, Häkkinen A, Haverkamp D, et al. Efficacy of tailored exercise therapy on physical functioning in patients with knee osteoarthritis and comorbidity: A randomized controlled trial. Arthritis Care Res (Hoboken). 2016 Aug 26. doi: 10.1002/acr.23013. [Epub ahead of print]

30. Goh SL, Persson MS, Bhattacharya A, Hall M, Doherty M, Zhang W. Relative efficacy of different types of exercise for treatment of knee and hip osteoarthritis: protocol for network meta-analysis of randomised controlled trials. Syst Rev. 2016 Sep 2;5(1):147.

31. Jorge RT, Souza MC, Chiari A, Jones A, Fernandes Ada R, Lombardi Júnior I, et al. Progressive resistance exercise in women with osteoarthritis of the knee: a randomized controlled trial. Clin Rehabil. 2015;29(3):234-43.

32. Visser AW, de Mutsert R, Bloem JL, Reijnierse M, Kazato H, le Cessie S,et al. Do knee osteoarthritis and fat-free mass interact in their impact on health-related quality of life in men? results from a population-based cohort. Arthritis Care Res (Hoboken) 2015;67(7):981-8.

Received: March 1, 2016

Reviewed: October 31, 2016

Accepted: November 8, 2016 